Supporting information

\title{
Wash-Free, Digital Immunoassay in Polydisperse Droplets
}

Samantha A. Byrnes**, Toan Huynh**, Tim C. Chang, Caitlin E. Anderson, James J. McDermott, Ciela I. Oncina, Bernhard H. Weigl, Kevin P. Nichols*

Center for In Vitro Diagnostics, Intellectual Ventures Laboratory, Bellevue, WA, USA

Corresponding Authors

*Samantha A. Byrnes: sbyrnes@intven.com

*Toan Huynh: toanhuynh@intven.com

*Kevin P. Nichols: knichols@intven.com

Intellectual Ventures Laboratory, 14360 SE Eastgate Way, Bellevue, WA, 98007, USA 


\section{DISTRIBUTION OF DROPLET VOLUMES}

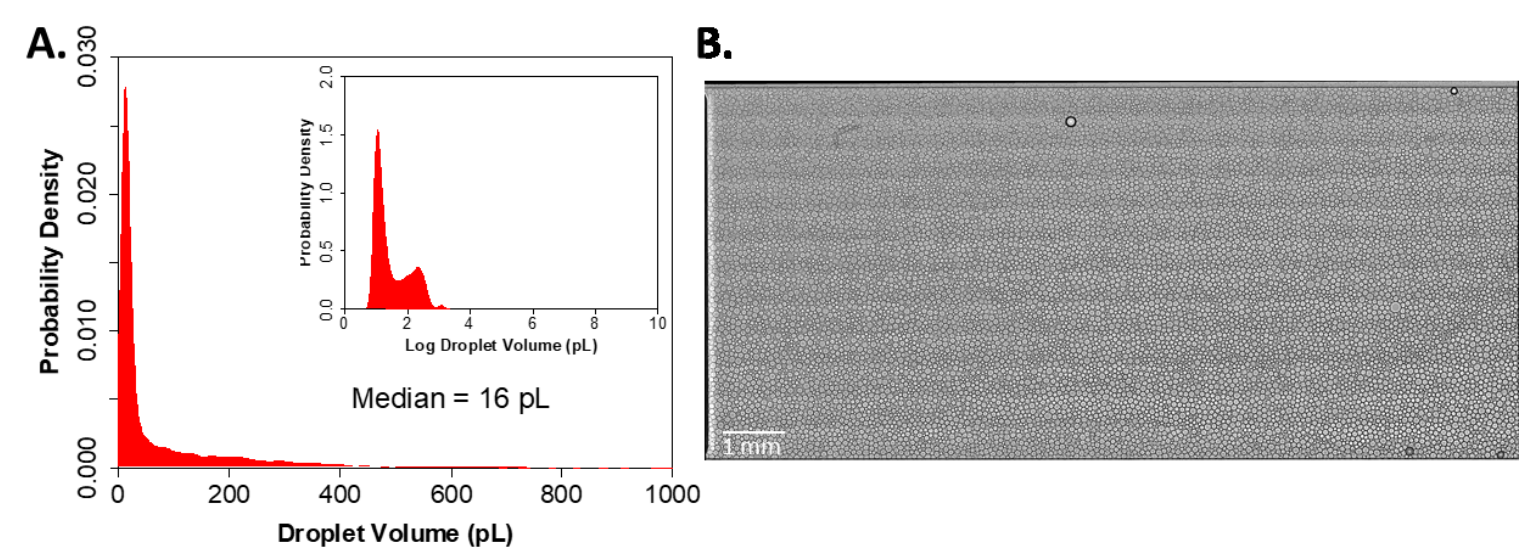

Figure S1. Polydisperse droplet distribution for the ddIA. A. Distribution of droplet volumes analyzed using MATLAB's imfindcircles function from the Image Processing Toolbox (a total of 9522 droplets were measured). The size range was set from $30-175$ pixels, with Sensitivity set to 0.92, and EdgeThreshold set to 0.12 . The resulting radii were converted to droplet volumes in $\mathrm{pL}$. Droplets had diameters ranging from 23.4 to $136.5 \mu \mathrm{m}$ with a median diameter of $31.3 \mu \mathrm{m}(16 \mathrm{pL})$. The inset shows the same data, but plotted on a log scale for droplet volumes. We've previously described the reproducibility of this droplet formation method. ${ }^{1}$ B. An example image of a polydisperse droplet sample used for our ddIA. The striations in the figure are a result of the imaging method. This image is a set of $26 \times 13$ individual images that are stitched together by our imaging software. The striations are the overlapping regions of adjacent images.

\section{PROXIMITY LIGATION ASSAY WITH QPCR: 3 V. 2 V. 1-STEP \\ METHODS}

The 3-step proximity ligation assay (PLA) with qPCR was run according to the manufacturer's protocol. All experiments were performed using recombinant human IL-8 as the target molecule (72 amino acids, $8.4 \mathrm{kDa}$ ). Briefly, sample was added to an antibody-oligo conjugate mix provided in the kit and incubated at room temperature or $37{ }^{\circ} \mathrm{C}$ for $15-80$ minutes. Following the initial incubation, ligase provided in the kit was added to the reaction solution and incubated at room temperature, $37^{\circ} \mathrm{C}$, or $60{ }^{\circ} \mathrm{C}$ for 10-30 minutes. After ligation, the qPCR master mix provided by the kit was added to the reaction solution and the following protocol was run on a BioRad CFX96 Real-Time PCR Detection instrument: $95{ }^{\circ} \mathrm{C}$ hold for 2 minutes, 40 cycles of $95{ }^{\circ} \mathrm{C}$ for 15 seconds and $60{ }^{\circ} \mathrm{C}$ for 1 minute. Results were read in the FAM channel after the $60{ }^{\circ} \mathrm{C}$ annealing/elongation step. For the 2-step reaction, either the binding and ligation or the ligation and qPCR reagents were added simultaneously. For the 1 -step reaction, all reagents were added at the same time. Multiple ligases were tested in the reaction by omitting the kit ligase and substituting in commercially purchased ligases (Taq DNA ligase, HiFi Taq DNA ligase, $9^{\circ} \mathrm{N}$ DNA ligase, thermo-stable 5'App ligase, or ampligase).

For complex sample testing, the target antigen was spiked into either plasma or whole blood at varying dilutions. No further sample preparation or clean-up was performed before testing plasma and blood samples in the single-step PLA.

\section{RESULTS}

The ProQuantum assay was originally designed to separate antibody-antigen binding, oligo ligation, and target oligo amplification into three separate steps. To optimize the assay towards our goal, we began by combining the first two reaction steps: binding and ligation. In general, the combination of these two steps saw a uniform decrease of 16-fold ( 4 Ct) in signal compared to the three-step reaction, but it also resulted in a reduced LoD. The combined binding and ligation step showed a decrease in background signal and reduced variation between replicates which improved the LoD of the assay compared to the standard threestep assay. Three step LoD: $0.56 \mathrm{pg} / \mathrm{mL}$ [95\% CI: $0.11-1.24 \mathrm{pg} / \mathrm{mL}]\left(0.07 \mathrm{pM}\right.$ [95\% CI: $0.01-0.15 \mathrm{pM}$ ]; $2.01 \times 10^{5}$ 
antigens [95\% CI: $4.09 \times 10^{4}-4.43 \times 10^{5}$ antigens]). Binding+ligation LoD: $0.01 \mathrm{pg} / \mathrm{mL}$ [95\% CI: $0.005-0.03$ $\mathrm{pg} / \mathrm{mL}](0.001 \mathrm{pM}$ [95\% CI: $0.0006-0.003 \mathrm{pM}] ; 4.30 \times 10^{3}$ antigens [ $95 \% \mathrm{CI}: 1.79 \times 10^{3}-1.00 \times 10^{4}$ antigens]).

Next, we varied the timing for the combined bindingligation step between 15-80 minutes to determine the reaction time that balanced true positive oligo-ligation driven by antigen-antibody binding and false positive oligo-ligation without target antigen. Optimizing reaction conditions, such as timing, may help minimize background signal while still allowing enough interaction time for true positive antibodyantigen binding to occur. For our initial test, a 15-minute binding-ligation step resulted in a low background, but also saw a significant decrease in positive signals, likely due to limited time for the antibodies and antigens to interact in solution. For this assay, 30-80 minutes of binding-ligation did not significantly impact the positive results, but a 60 -minute reaction resulted in the lowest background signal.

We also explored a two-step reaction that varied the timing of ligase addition to the reaction. When ligase is added at the start of the binding step, there is a decrease in signal for both the positive and negative samples which actually leads to an improved LoD due to the low background. This result agrees with the data comparing the three-step and two-step reaction above. LoD of ligase with binding $0.01 \mathrm{pg} / \mathrm{mL}$ [95\% CI: $0.005-0.03 \mathrm{pg} / \mathrm{mL}](0.001 \mathrm{pM}$ [95\% CI: $0.0006-0.003$ $\mathrm{pM}] ; 4.30 \times 10^{3}$ antigens [95\% CI: $1.79 \times 10^{3}-1.00 \times 10^{4}$ antigens]). LoD of ligase post binding when PCR reagents are present during binding $0.20 \mathrm{pg} / \mathrm{mL}$ [95\% CI: $0.10-0.30$ $\mathrm{pg} / \mathrm{mL}]\left(0.02 \mathrm{pM}[95 \%\right.$ CI: $0.01-0.04 \mathrm{pM}] ; 7.10 \times 10^{4}$ antigens $\left[3.51 \times 10^{4}-1.06 \times 10^{5}\right.$ antigens $]$ ).

Further, we tested different ligases to potentially improve signals from positive samples while maintaining a low background. The main goal of these tests was to identify a thermostable ligase that worked well in the PLA. Ideally, the ligase would not be optimal at room temperature during antigen-antibody binding. Then, the ligase could be "turned on' by increasing the temperature. This work tested five additional ligases (Taq DNA ligase, HiFi Taq DNA ligase, $9^{\circ} \mathrm{N}$ DNA ligase, thermostable 5'App ligase, or ampligase), but none were compatible with the ProQuantum kit (results not shown).

The final test was to collapse the three reagent addition steps (binding, ligation, and amplification) into one at the start of the reaction. As described above, the presence of the ligase during binding decreased the background signal and variation between samples. This led us to predict a similar decrease in the background for the one-step reaction. Surprisingly, this was not the case and the one-step reaction resulted in a higher average background than the three-step reaction. We did observe that the presence of the amplification reagents during binding and ligation did increase the background (Figure S2) which is consistent with the results from the single-step assay in bulk.

\section{UNIT CONVERSION}

According to the manufacturer, the recombinant human IL-8 used in this work is 72 amino acids and $8.4 \mathrm{kDa}$ (https://www.thermofisher.com/elisa/product/IL-8-Human-ProQuantum-Immunoassay-Kit/A35575).

$$
\begin{gathered}
\frac{1 p g}{m L} \times \frac{m o l e}{8.4 k D a} \times \frac{1000 m L}{L}=0.12 p M \\
\frac{1 p g}{m L} \times \frac{1 m L}{1 \times 10^{3} \mu L} \times 5 \mu L \text { input sample }=0.005 \mathrm{pg} \text { input } \\
0.005 \mathrm{pg} \times \frac{\text { mole }}{8.4 \mathrm{kDa}} \times \frac{6.02 \times 10^{23} \text { molecules }}{1 \text { mole }}=3.6 \times 10^{5} \text { molecules of antigen }
\end{gathered}
$$




\section{WEIGHTING FOR NONLINEAR REGRESION, AS PART OF THE CALCULATION OF LIMITS OF DETECTION}
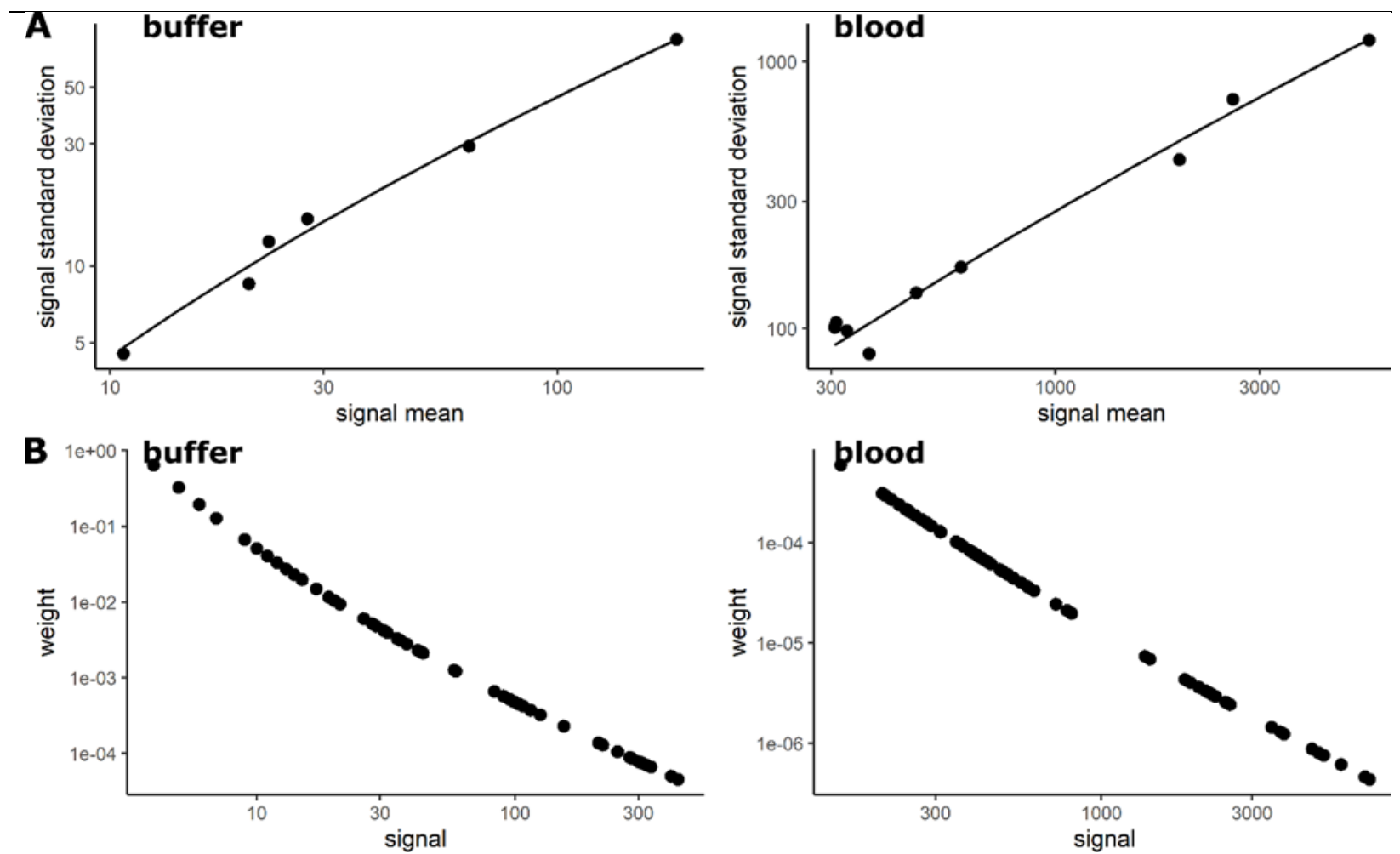

Figure S3. Data variance functions (DVFs) ${ }^{2}$ for weighting in fitting for the calculation of limits of detection, for cases of buffer and blood as the sample matrices. The experimental datasets are the same as those described in Figure 1 (buffer) and Figure 2 (blood). A. Plots show signal standard deviations and signal means calculated from the datasets. The fitting was done using the equation $y=e^{a+b \sqrt{\log (x)}}$ (which is equivalent to $\log (y)=a+b \sqrt{\log (x)}$, as motivated by inspection of the data points). B. Plots show weights $\left(1 /\right.$ standard deviation $\left.{ }^{2}\right)$ versus signals. 

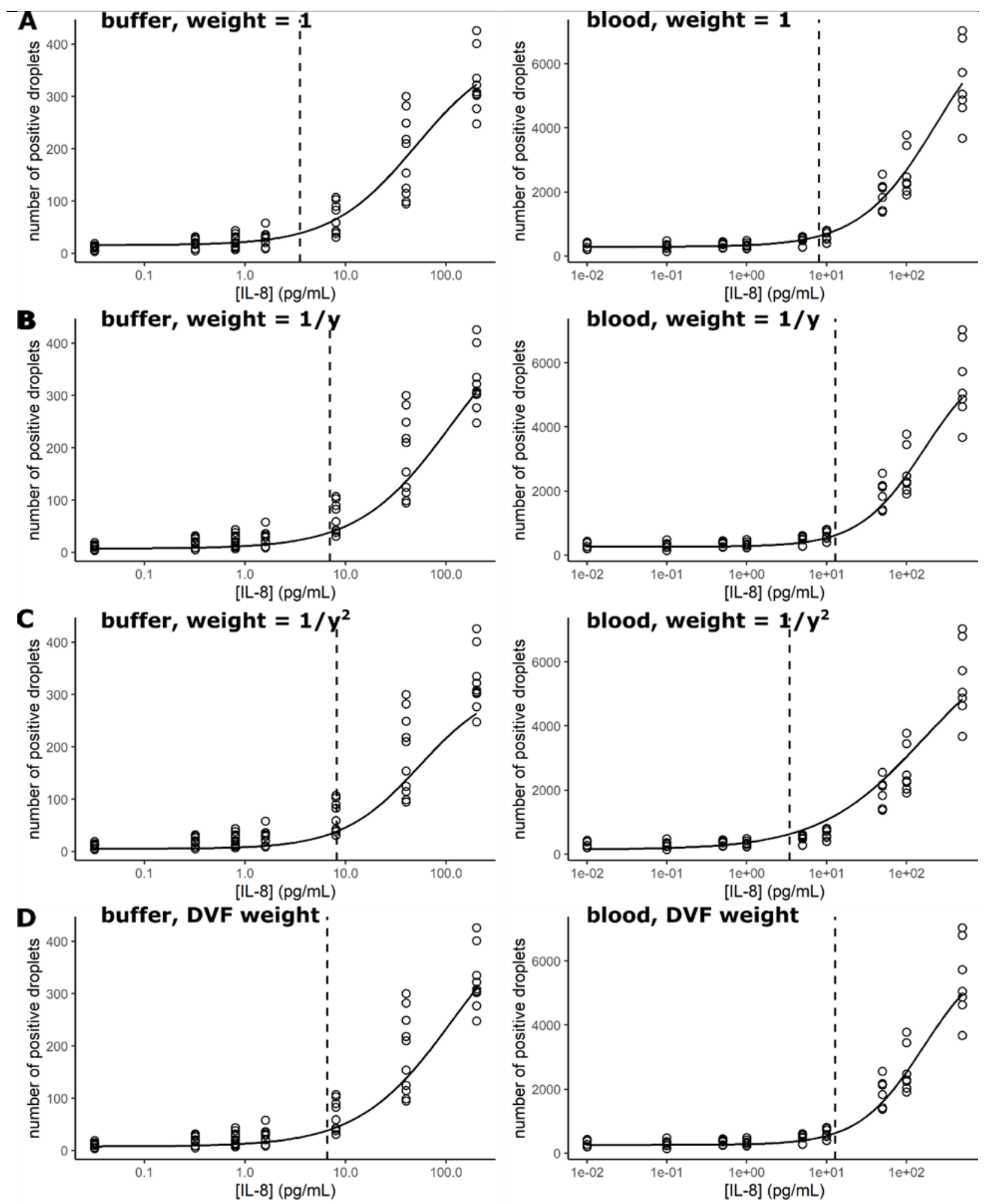

Figure S4. Weighting in fitting for the calculation of limits of detection. Plots show data points and the fitted curves with weight $=1(A)$, weight $=1 / y(B)$, weight $=1 / y^{2}(C)$, and weight $=1 /$ variance fitted from the data (DVF weight, Figure S3) (D), for the cases of assays in buffer and in blood. Points at 0 input analyte concentration are represented on the log scale at concentrations 10 times smaller than the lowest positive concentrations. The experimental datasets are the same as those described in Figure 1 (buffer) and Figure 2 (blood). 
Table S1. Limits of detections at using different weighting options. The experimental datasets are the same as those described in Figure 1 (buffer) and Figure 2 (blood).

\begin{tabular}{l|l|l|l|l}
\hline Matrix & LoD $(\mathbf{p g} / \mathbf{m L})$ & $\begin{array}{l}\text { Confidence interval, } \\
\text { lower bound }\end{array}$ & $\begin{array}{l}\text { Confidence interval, } \\
\text { upperbound }\end{array}$ & Weighting \\
\hline \multirow{5}{*}{ buffer } & 3.53 & 0.67 & 6.39 & 14.41 \\
& 6.98 & 0 & 57.38 & 1 \\
& 8.20 & 0 & 9.27 & $1 / \mathrm{y}$ \\
\hline \multirow{5}{*}{ blood } & 6.61 & 4.95 & 12.40 & Data variance function (Figure S5.5) \\
\hline & 13.0 & 3.66 & 19.7 & 1 \\
& 3.42 & 6.3 & $\mathrm{n} / \mathrm{a}$ & $1 / \mathrm{y}$ \\
& 12.8 & $\mathrm{n} / \mathrm{a}$ & 16.8 & $1 / \mathrm{y}^{2}$ \\
Data variance function (Figure S5.5) \\
\hline
\end{tabular}


Table S2. Comparison of the Simoa system and our novel ddIA system with a focus on potential use in LRS and the POC, adapted from Rivnak et al. ${ }^{5}$

*The Simoa IL-8 kit notes that the following additional materials are required, but not provided with the kit, further increasing the costs of consumables: Simoa Wash Buffer 1, Simoa Wash Buffer 2, Simoa Sealing Oil, Simoa cuvettes, Simoa disposable pipettor tips, Simoa Discs

**Our ddIA is designed to be flexible with respect to assay container - it is currently compatible with a variety of tubes and wellplates and does not require additional buffers (such as wash buffers), which should keep consumable costs significantly lower than the Simoa system

\begin{tabular}{|c|c|c|}
\hline Platform Characteristic & Simoa system & ddIA (this work) \\
\hline Sensitivity & $10 \mathrm{~s} \mathrm{fg} / \mathrm{mL}$ & $1000 \mathrm{~s} \mathrm{fg} / \mathrm{mL}$ \\
\hline $\begin{array}{l}\text { Specialized equipment } \\
\text { needs }\end{array}$ & $\begin{array}{l}\text {-Microfluidic discs for compartmentalization } \\
\text { Automated liquid handling robot to execute } \\
\text { multiple steps, including washing }\end{array}$ & None \\
\hline Equipment costs & $\$ \$ \$ \$$ & $\$-\$ \$$ \\
\hline Consumable costs & $\begin{array}{l}\$ \$ \$ \text { (including Simoa discs which are specialized } \\
\text { and required to run the assay)* }\end{array}$ & $\begin{array}{l}\text { \$ (this method can be run with any tubes or } \\
\text { well-plates that fit in a standard lab } \\
\text { thermocycler)** }\end{array}$ \\
\hline $\begin{array}{l}\text { In-assay calibration } \\
\text { required }\end{array}$ & $\begin{array}{l}\text { Yes, kit inserts include "Required Calibrator" as } \\
\text { an } 8 \text {-point calibration curve and a } 2 \text {-point } \\
\text { control }{ }^{3} \text { even if only running a single sample; } \\
\text { "Calibrator is 1-time use only"3 }\end{array}$ & $\begin{array}{l}\text { No calibration curve required; data analysis } \\
\text { may include calibration }\end{array}$ \\
\hline Number of user steps & $\begin{array}{l}7 \text { - prepare calibrators, prepare controls, prepare } \\
\text { reagents (beads and sample diluent), pipette } \\
\text { samples into plate, load provided reagent bottles } \\
\text { into machine, set-up specifics in machine } \\
\text { software, load reaction plate into machine and } \\
\text { run }\end{array}$ & $\begin{array}{l}5 \text { - prepare reagents (mix ligase, master mix, } \\
\text { and oil), pipette samples into tubes or plate, } \\
\text { generate droplets ( } 30 \text { seconds), heat tubes or } \\
\text { plate, analyze (microscope or simple reader) }\end{array}$ \\
\hline Flexibility for user & $\begin{array}{l}\text { Minimal - the system is highly optimized for the } \\
\text { given applications and steps run in a specific } \\
\text { order; must always run a full 8-point calibration } \\
\text { and 2-point control3; may be able to run with } \\
\text { common laboratory equipment }\end{array}$ & $\begin{array}{l}\text { Moderate - users can run a single sample or } \\
\text { multiple samples simultaneously, can easily } \\
\text { change assay specifics like temperature and } \\
\text { time, can use a variety of assay containers }\end{array}$ \\
\hline Use location & Centralized lab only & $\begin{array}{l}\text { POC/tertiary healthcare provider with } \\
\text { minimum instrument capabilities through } \\
\text { centralized lab }\end{array}$ \\
\hline $\begin{array}{l}\text { Amount of user } \\
\text { training required }\end{array}$ & $\begin{array}{l}\text { Extensive, multiple days - driven by complexity } \\
\text { of learning to operate the Simoa HD-1/HD-X } \\
\text { Analyzer }\end{array}$ & $\begin{array}{l}\text { Minimum - technicians with limited } \\
\text { laboratory skills like pipetting could easily } \\
\text { run this assay }\end{array}$ \\
\hline
\end{tabular}



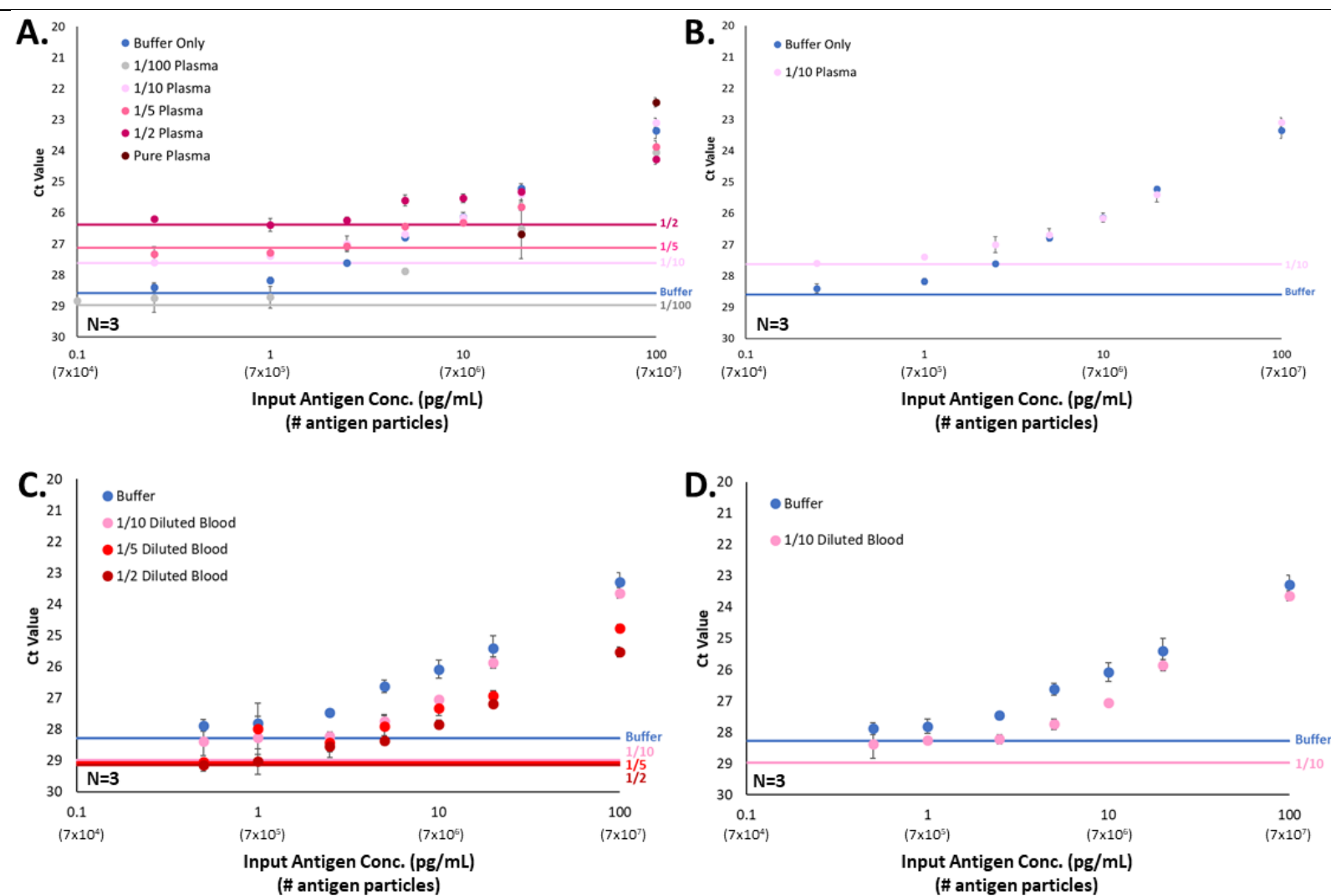

Figure S5. Optimization of human plasma and blood dilutions in a bulk, one-step reaction. These results helped narrow down the dilution to test in droplet-based reactions. Averages of $\mathrm{N}=3$ are reported with error bars representing $+/-$ one standard deviation for each data point. De-identified, unspun human whole blood and plasma was sourced from Biological Specialty. A. Pure plasma without dilution was tested in the bulk, one-step reaction as well as dilutions of 1:100. More concentrated plasma samples showed higher background signals. B. The 1:10 input dilution (1:100 final) was chosen as the plasma dilution to test in our ddIA due to its low dilution factor and moderate increase in background signal compared to reaction in buffer. $\mathbf{C}$. The most concentrated blood tested was with a 1:2 dilution which showed a significant decrease in signal at all concentrations tested. D. Similar to plasma, the 1:10 dilution was chosen as the blood dilution to test in our ddIA. 


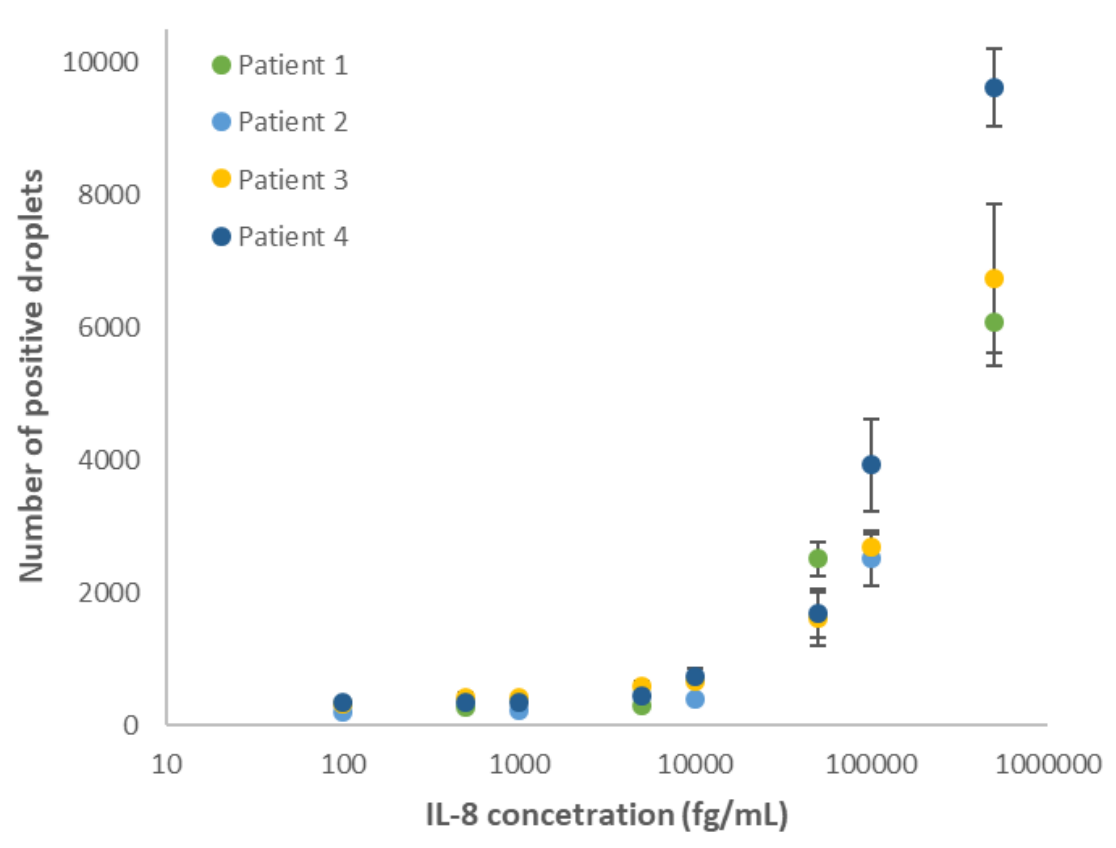

Figure S6. Single-step ddIA tested with whole blood samples from four healthy donors. Assay LoD was calculated using 1:10 input diluted (1:100 final) whole blood from 3 biological replicates run for each of the four donors. While baseline IL-8 concentrations can differ from one donor to another, plasma IL-8 levels are most often below the threshold of traditional laboratory techniques [Reinsberg 2000]. However, conditions including allergies or autoimmune responses can lend otherwise healthy donors to have IL-8 levels up to $\sim 100 \mathrm{pg} / \mathrm{mL} .{ }^{4,5}$

\section{RESOLUTION OF THE ASSAY}

Table S3. Resolution of the assay in buffer and dilute whole blood. Using 1-sided unpaired t-tests, we obtained the p-values. Two concentrations are considered resolved when the $\mathrm{p}$-value is not larger than 0.05 . Only concentrations just below the limits of detection (Table S1) or larger are considered. The experimental datasets are the same as those described in Figure 1A (buffer) and Figure 1B (blood).

\begin{tabular}{c|c|c|c|c|c}
\hline Matrix & Lower concentration $\mathbf{( p g / m L )}$ & Upper concentration $\mathbf{( p g / m L )}$ & Fold increase & p-value & Resolved \\
\hline \multirow{3}{*}{ buffer } & 1.6 & 8 & 5 & 0.002192 & yes \\
& 8 & 40 & 5 & 0.000307 & yes \\
& 40 & 200 & 5 & 0.000132 & yes \\
\hline \multirow{3}{*}{ blood } & 5 & 10 & 2 & 0.072722 & no \\
& 10 & 50 & 5 & $3.22 \mathrm{E}-05$ & yes \\
& 50 & 100 & 2 & 0.034523 & yes \\
& 100 & 500 & 5 & 0.000191 & yes \\
\hline
\end{tabular}

\section{REFERENCES}

1 S. A. Byrnes, E. A. Phillips, T. Huynh, B. H. Weigl and K. P. Nichols, Analyst, 2018, 143, 2828-2836.

2 J. Tellinghuisen, Anal. Chem., 2019, 91, 8715-8722.

3 Simoa ${ }^{\circledR} I L-8$ Advantage Kit Kit Instructions for HD-1/HD-X, Quanterix Corporation Inc, 2018.

4 J. Zhang and C. Bai, Tanaffos, 2017, 16, 260-269.

5 C. Marie, C. Fitting, C. Cheval, M. R. Losser, J. Carlet, D. Payen, K. Foster and J. M. Cavaillon, Infect. Immun., 1997, 65, 865-871.

6. A. J. Rivnak, D. M. Rissin, C. W. Kan, L. Song, M. W. fishburn, T. Piech, T. G. Campbell, D. R. DuPont, M. Gardel, S. Sullivan, B. A. Pink, C. G. Cabrera, D. R. Fournier, and D. C. Duffy. Journal of Immuno. Methods, 2015, 424, $20-27$. 